\title{
ENHANCEMENTS TO THE CALIOP AEROSOL SUBTYPING AND LIDAR RATIO SELECTION ALGORITHMS FOR LEVEL II VERSION 4
}

\author{
A. Omar ${ }^{1}$, J. Tackett ${ }^{2}$, M-H. Kim ${ }^{3}$, M. Vaughan ${ }^{1}$, J. Kar ${ }^{2}$, C. Trepte ${ }^{1}$, D. Winker ${ }^{1}$ \\ ${ }^{I}$ NASA Langley Research Center, Atmospheric Sciences, MailStop 475, Hampton, VA 23681 ali.h.omar@nasa.gov \\ ${ }^{2}$ Science Systems Applications Inc (SSAI), Hampton, VA, \\ ${ }^{3}$ NASA NPP (USRA)
}

\section{ABSTRACT}

Several enhancements have been implemented for the version 4 aerosol subtyping and lidar ratio selection algorithms of Cloud Aerosol Lidar with Orthogonal Polarization (CALIOP). Version 4 eliminates the confusion between smoke and clean marine aerosols seen in version 3 by modifications to the elevated layer flag definitions used to identify smoke aerosols over the ocean. To differentiate between mixtures of dust and smoke, and dust and marine aerosols, a new aerosol type will be added in the version 4 data products. In the marine boundary layer, moderately depolarizing aerosols are no longer modeled as mixtures of dust and smoke (polluted dust) but rather as mixtures of dust and seasalt (dusty marine). Some lidar ratios have been updated in the version 4 algorithms. In particular, the dust lidar ratios have been adjusted to reflect the latest measurements and model studies.

\section{INTRODUCTION}

The version 4 aerosol subtyping algorithms are considerably improved over the earlier versions. They initially employ more accurately calibrated level 1 data and the MERRA-2 meteorological data. These discussed in detail in the data quality summaries (https://goo.gl/qVRmd8). The version 4 Level 2 aerosol subtyping algorithm is preceded by a much improved cloud aerosol discrimination algorithm and includes improvements in the tropospheric aerosol subtyping algorithm, and new schemes for stratospheric aerosol subtyping (c.f. [1]) and updated lidar ratios. Version 4 permits identification of all aerosol types over snow/tundra land surface types (Polar Regions) and therefore correctly accounts for transport of assorted aerosol types to polar regions, especially to the Arctic. Another significant improvement is that the version 4 algorithms account for the settling of dust plumes into the marine boundary layer which results in mixtures of dust and seasalt aerosols.

\section{POLLUTED DUST AND DUSTY MARINE AEROSOL DEFINITION}

Several comparisons of CALIOP's lidar ratios with High Spectral Resolution Lidar (HSRL) over

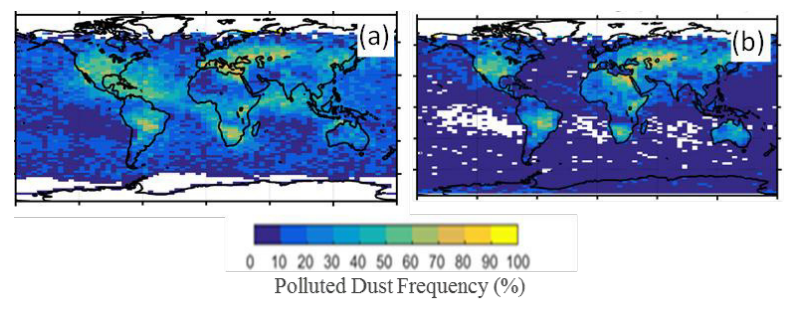

Figure 1. Polluted dust frequency for (a) version 3 and (b) version 4 for June-July-August 2008 nighttime layers.

the ocean show that the lidar ratio $\left(S_{\mathrm{a}}\right)$ estimates for dust and marine are in agreement. However, these same comparisons also show that the CALIOP lidar ratio assigned for polluted dust (55 sr) is typically much larger that the lidar ratio measured by the HSRL ( $35 \mathrm{sr})$. [2]. Since $S_{a}$ is a good proxy for aerosol type, this suggests that CALIOP's aerosol model is wrong for moderately depolarizing cases near the ocean surface and points to a need to define a more representative aerosol type. The version 4 aerosol subtyping algorithm now include a dusty marine (dust + marine) aerosol type, with a $S_{a}$ value of $37 \mathrm{sr}$, for moderately depolarizing aerosols in and near the marine boundary layer (altitudes less than $2.5 \mathrm{~km}$ above the ocean surface). Figure 1 illustrates the improvement in the distributions of polluted dust over version 3. Though the distributions of polluted dust in version 4 are more reasonable, high frequencies in the northern Pacific and Indian Ocean persist. In version 3 smoke and polluted continental aerosol layers are occasionally misclassified as marine layers near continental outflows. The map in Figure 2(a) shows the altitude at which clean marine aerosols 
are most frequently found in version 3 . There is a high frequency of elevated marine layers on the south west coast of Africa and the region stretching from the Kamchatka peninsula to the Sea of Japan. Figures 2 (b) - (c) show a case study of this misclassification arising from a number of bugs and incorrect elevated layer flag thresholds. Note the large number of elevated marine layers and attached polluted continental layers
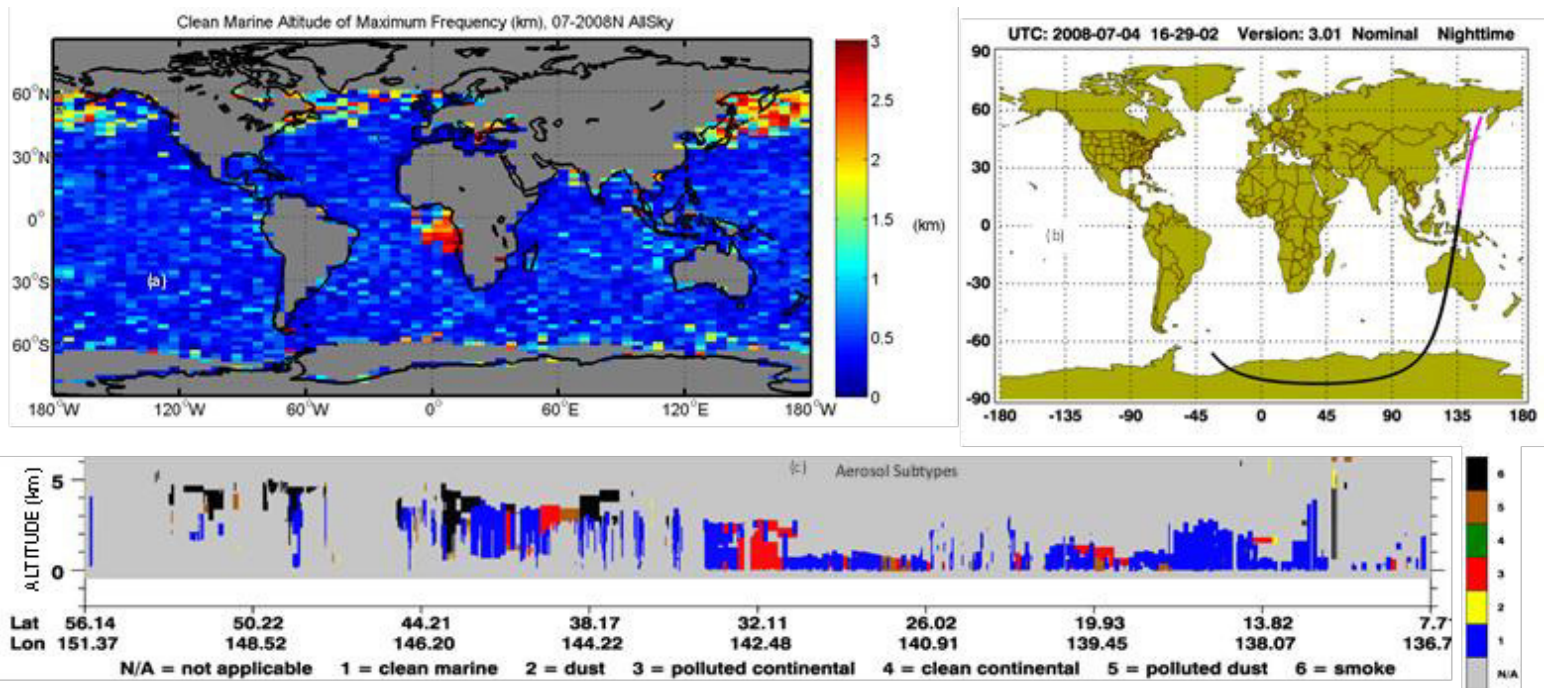

Figure 2. (a) The altitude of maximum frequency of marine layers in July 2007, (b) night time orbit and (c) the corresponding subtypes.
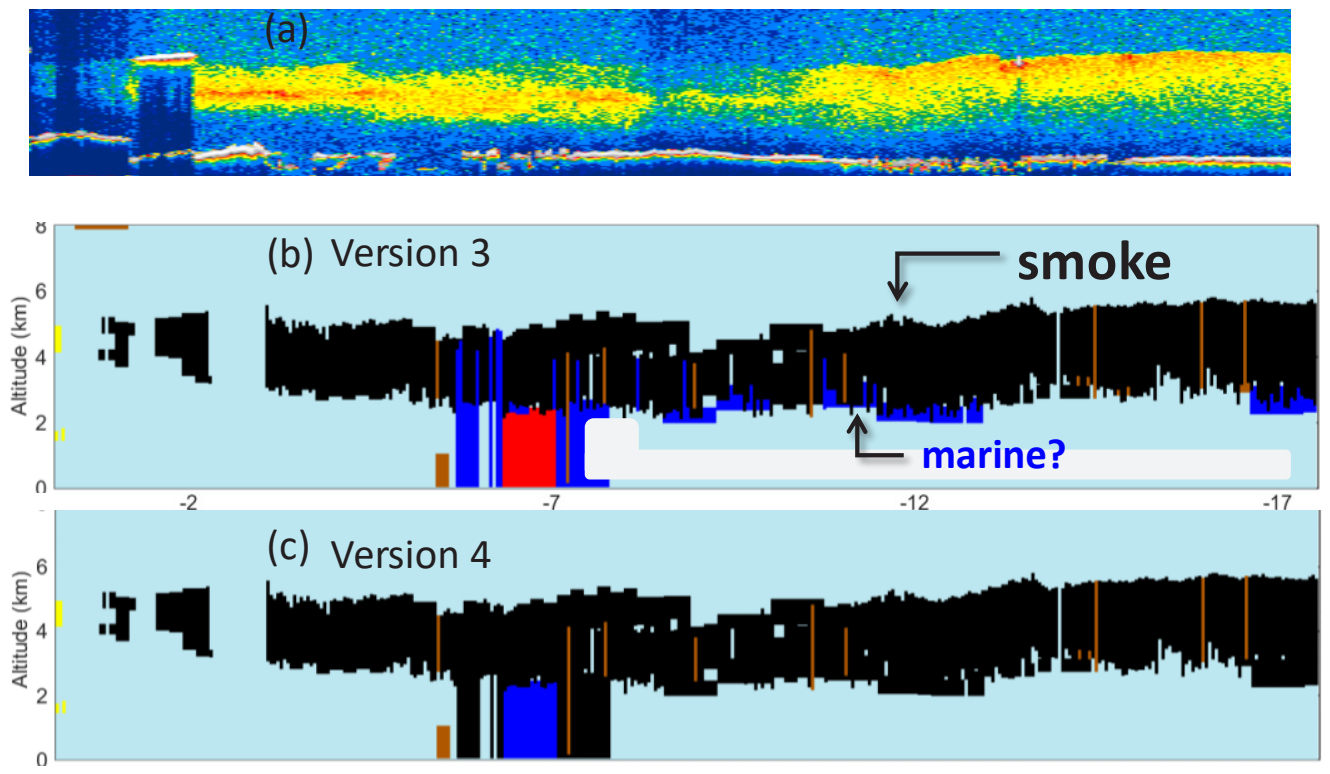

Figure 3(a) Browse image of an aerosol layer of the Gulf of Guinea, and (b) the version 3 and (c) version 4 classifications of the aerosol layer showing smoke in black, marine in blue and polluted dust in brown.

\section{MARINE AND SMOKE TYPES}

In version 3 , smoke is a non-depolarizing and elevated aerosol. However, the definition also included 'elevated' included a threshold 
geometric thickness which resulted in spurious classifications and the large frequencies of smoke misclassified as marine shown in Figure 2 (a) above. Figure 3 shows a case study of a robust smoke layer (a) off the Gulf of Guinea and its version 3 classification (b). The version 4 algorithm, illustrated by Fig 3(c), identifies Smoke as non-depolarizing and elevated (i.e., layer top $>2.5 \mathrm{~km}$ ) irrespective of the geometric thickness. In the version 4 subtyping products, fewer smoke layers are misclassified as marine and the 'striping' by marine layers in smoke plume is substantially reduced.

\section{LIDAR RATIOS}

[3] developed a technique that takes advantage of the relatively small variability of the lidar ratio for water clouds and uses opaque water clouds as a reference to determine the optical depth of overlying transparent aerosol or cirrus layers. [4] applied this technique to CALIOP level 1 measurements in dust region off the coast of $\mathrm{W}$. Africa to retrieve, unambiguously, distributions of dust and smoke lidar ratios.
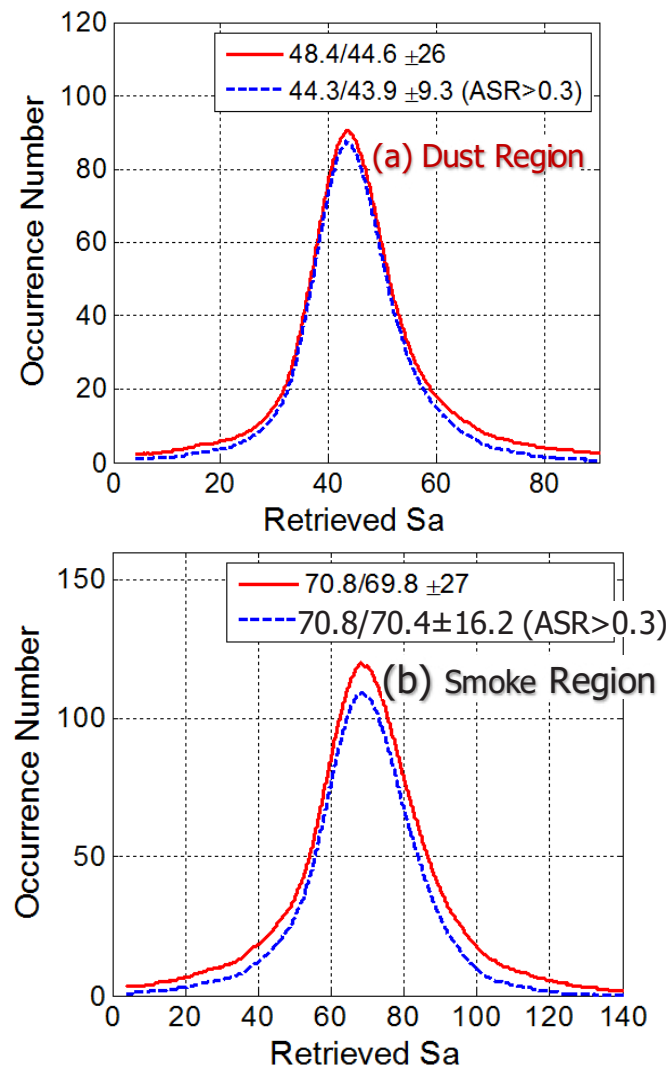

Figure 4. Multiyear retrieval of dust and smoke lidar ratios (Liu et al. 2015). Lidar ratios of dust and smoke are well constrained around $44 \mathrm{sr}$ and
$70 \mathrm{sr}$, respectively. The blue dotted lines are for aerosol scattering ratios $(A S R)>0.3$.

These are shown in Figure 4 and are used to inform the adjustment of the dust $\mathrm{S}_{\mathrm{a}}(44 \mathrm{sr})$ for version 4 products. While the smoke $S_{a}$ remains unchanged from version 3 , the uncertainty is reduced. The lidar ratios and uncertainties used for all version 4 aerosol subtypes are listed in Table 1. Version 4 assumes the 532-nm and 1064nm lidar ratios are the same.

Table 1. $532 \mathrm{~nm}$ Lidar Ratios of Versions 3 and 4

\begin{tabular}{|c|c|c|}
\hline \multirow{2}{*}{ Layer Type } & \multicolumn{2}{|c|}{$532 \mathrm{~nm}$ Lidar Ratios (sr) } \\
\cline { 2 - 3 } & version 3 & version 4 \\
\hline Dust & $40 \pm 20$ & $44 \pm 9^{\mathrm{A}, \mathrm{B}}$ \\
\hline Smoke & $70 \pm 28$ & $70 \pm 16^{\mathrm{A}}$ \\
\hline Clean Continental & $35 \pm 16$ & $53 \pm 11^{\mathrm{C}}$ \\
\hline Polluted Continental & $70 \pm 25$ & $70 \pm 25$ \\
\hline Polluted Dust & $55 \pm 22$ & $55 \pm 22^{\mathrm{D}}$ \\
\hline Clean Marine & $20 \pm 6$ & $23 \pm 5^{\mathrm{E}}$ \\
\hline Dusty Marine & & $37 \pm 15^{\mathrm{F}}$ \\
\hline
\end{tabular}

$\mathrm{S}_{\mathrm{a}}$ and uncertainty based on CALIPSO constrained retrievals by Liu et al. (2015)

B Based HSRL measurements of transported Saharan dust. No $\lambda$ dependence based on [5]

${ }^{\mathrm{C}} \mathrm{S}_{\mathrm{a}}$ measured by HSRL for layers classified as clean continental by CALIPSO [6]

${ }^{D}$ Based on the microphysical measurements made during NAMMA. $S_{a}$ values in agreement with [7] and $[8]$

E $S_{a}$ measured by HSRL in multiple field campaigns, [8] No $\lambda$ dependence based on [9]), [10] , [7]

${ }^{\mathrm{F}} \mathrm{S}_{\mathrm{a}}$ based on mixture of dust and marine aerosol ( $65 / 35$ by surface area). Uncertainty is larger than either dust or marine alone.

\section{SUMMARY}

The aerosol subtyping algorithm in version 4 includes a number of improvements. Specifically, polluted dust is identified in more realistic regions compared to version 3 which showed widespread misclassification. A new dusty marine aerosol type is added to account for dust settling into the marine boundary layer. Smoke layers are no 
longer misclassified as clean marine aerosol, improving aerosol optical depth estimates for smoke layers in oceanic smoke outflow regions. Aerosol lidar ratios have also been updated in version 4 to reflect current understanding by independent instruments. In addition to the improvements discussed here, stratospheric aerosol types are now identified (volcanic ash, sulfate, smoke, PSC aerosol). Descriptions of aerosol subtyping improvements for version 4 are available on the CALIPSO Data Users Guide [https://www-

calipso.larc.nasa.gov/resources/calipso_users_gui de/qs/cal_lid_12_all_v4-10.php].

[1] Vaughan, M., A. Garnier, J. Tackett, M. Avery, S. Young, J. Kar, B. Getzewich, A. Omar, Z. Liu, K.-P. Lee, X. Cai, S. Zeng, Y. Hu, J. Lambeth, R. Ryan, B. Magill, S. Rodier, T. Murray, K. Beaumont, P. Detweiler, P. Lucker, J. Pelon, D. Winker, and C. Trepte, "Introducing CALIPSO's Version 4 Level 2 Lidar Data Products," in International Laser Radar Conference (ILRC), Bucharest, Romania, 2017.

[2] Rogers, R. R., C. A. Hostetler, J. W. Hair, R. A. Ferrare, Z. Liu, M. D. Obland, D. B. Harper, A. L. Cook, K. A. Powell, M. A. Vaughan, and D. M. Winker, "Assessment of the CALIPSO Lidar $532 \mathrm{~nm}$ attenuated backscatter calibration using the NASA LaRC airborne High Spectral Resolution Lidar," Atmos. Chem. Phys., vol. 11, pp. 1295-1311, 2011.

[3] Hu, Y., M. Vaughan, Z. Liu, K. Powell, and S. Rodier, "Retrieving Optical Depths and Lidar Ratios for Transparent Layers Above Opaque Water Clouds From CALIPSO Lidar Measurements," IEEE Geoscience and Remote Sensing Letters, vol. 4, pp. 523-526, 2007.

[4] Liu, Z., D. Winker, A. Omar, M. Vaughan, J. Kar, C. Trepte, Y. Hu, and G. Schuster, "Evaluation of CALIOP $532 \mathrm{~nm}$ AOD over opaque water clouds," Atmospheric chemistry and physics discussions, vol. 14, pp. 2358323637, 2014.

[5] Tesche, M., A. Ansmann, D. Muller, D. Althausen, I. Mattis, B. Heese, V. Freudenthaler, M. Wiegner, M. Esselborn, G. Pisani, and P. Knippertz, "Vertical profiling of Saharan dust with Raman lidars and airborne HSRL in southern Morocco during SAMUM," Tellus B, vol. 61, pp. 144-164, Feb 2009.
[6] Rogers, R. R., M. A. Vaughan, C. A. Hostetler, S. P. Burton, R. A. Ferrare, S. A. Young, J. W. Hair, M. D. Obland, D. B. Harper, A. L. Cook, and D. M. Winker, "Looking through the haze: evaluating the CALIPSO level 2 aerosol optical depth using airborne high spectral resolution lidar data," Atmos. Meas. Tech., vol. 7, pp. 4317-4340, 2014.

[7] Papagiannopoulos, N., L. Mona, L. AladosArboledas, V. Amiridis, H. Baars, I. Binietoglou, D. Bortoli, G. D'Amico, A. Giunta, J. L. Guerrero-Rascado, A. Schwarz, S. Pereira, N. Spinelli, U. Wandinger, X. Wang, and G. Pappalardo, "CALIPSO climatological products: evaluation and suggestions from EARLINET," Atmos. Chem. Phys., vol. 16, pp. 2341-2357, 2016.

[8] Muller, D., A. Ansmann, I. Mattis, M. Tesche, U. Wandinger, D. Althausen, and G. Pisani, "Aerosol-type-dependent lidar ratios observed with Raman lidar," J. Geophys. Res., vol. 112, Aug 172007.

[9] Sayer, A. M., A. Smirnov, N. C. Hsu, and B. N. Holben, "A pure marine aerosol model, for use in remote sensing applications," Journal of Geophysical Research: Atmospheres, vol. 117, pp. n/a-n/a, 2012.

[10] Josset, D., J. Pelon, Y. Hu, R. Rogers, Z. Liu, A. Omar, M. Vaughan, P. w. Zhai, and I. Team, "Global scale lidar ratio retrieval over the ocean," presented at the 26th International Laser Radar Conference (ILRC 26), Porto Heli, Greece, 2012. 